\title{
Clinical and Radiographic Evaluation of the Healing After MTA Application on Mechanical Furcal Perforations in Primary Molars-part2
}

\author{
Baraa Aldayri*, Abdul Wahab Nourallah ${ }^{1}$, Faek Badr ${ }^{2}$ \\ ${ }^{1}$ Associate Professor, Department of pediatric dentistry, Tishreen University, Lattakia, Syria \\ Email: abdulnourallah@tishreen.edu.sy. \\ ${ }^{2}$ Associate Professor, Department of pediatric dentistry, Tishreen University, Lattakia, Syria. \\ Email: faekbadr@gmail.com.
}

*Correspondence: Master student, Department of pediatric dentistry, Tishreen University, Lattakia, Syria.

Email: baraa.aldayri89@gmail.com.

\section{Abstract:}

Aim: aim of this study is to evaluate the clinical and radiographic healing after repairing mechanical furcal perforations that occurred in primary molars by using MTA (Mineral Trioxide Aggregate) and search in some factors that may affect the prognosis of the treatment. Materials \& Methods: we had 34 primary molars in 32 children aged 5-10 years, were treated by using MTA material after the occurrence of furcal perforation during pulpotomy procedure. Cases had been followed clinically and radiographically within 12 months. Statistical analyses were performed at $p$-value $=0.05$. Results: All teeth were asymptomatic at the first week. Overall success rate was $79.3 \%$. There was no significant statistically differences between overallsuccess rates according to the perforation size and continues bleeding in the furcation area ( $p$-value $>0.05)$. Conclusions: latrogenic furcal perforations that may occur during pulpotomy in primary molars can be treated successfully by using MTA, and small sized- perforations may have more favorable prognosis than the large ones.

Key words: Primary teeth, Pulpotomy, furcal perforation, perforation size.

\section{Introduction:}

Preserving primary teeth healthy until the normal eruption of the permanent successor is a very important matter to preserve dental arch's function and shape [1]. Preventive pulp treatment in primary teeth aims to preserving the pulp vitality subsequently these teeth until normal exfoliation [2,3], latrogenic problems may be occur with pre-graduated students during the treatments of children because of the limited experiences especially with young children [3]. Furcation perforation is an undesirable accident commonly occurs during open access of the pulp chamber or orifices exploration and affect the treatment prognosis [4,5]. Repairing furcal 
perforations in primary molars has become more important than extraction to extend the duration of them in the mouth and prevent from the premature loss[5].

\subsection{Perforations:}

The AAEs (American Association of Endodontists) glossary of endodontic terms defined the perforation as "the mechanical or pathologic communication between root canal system and external tooth surface [6]. Perforation may occur as a result of a large carious lesion in the floor of the pulp chamber, internal/external pathologic resorption, to the wrong performance during pulp treatment $[7,8]$ or the iatrogenic factors during open access and coronal shaping [9]. Furcal perforations usually occur as a result of insufficient knowledge of the pulp chamber anatomy or dental malalignment or failure in estimation of the anatomical differences, in addition to that calcifications may increase the risk of perforation occurrence and lead to destruction of the dentinal wall of the root or the floor of the pulp chamber with the covered cementum [10]. If these perforations will not be treated they will be followed by a bacterial contamination, periodontal ligament destruction, inflammation and bone resorption and/or necrosis [8,11-13] which leads in turn to a chronic inflammatory response in periodontal tissues (described as a granulomas tissue) that may lead to irreversible loss of the attachment and subsequently losing the teeth [14].

The prognosis of the perforations depends on the capability to repair them and preventing bacterial contamination [15-16]. Numerous factors affects the ability on infection control in perforation site subsequently the material capacity on sealing the lesion, those factors include time from occurrence to repairing, size, shape, location, repairing material $[5,8,11,15,17,18]$, patient's sex and age $[19,20]$, tooth position in the mouth (upper/lower) [21], experiences of the clinicians [22] and the presence of lesion and/or direct communication between the perforation site and the oral cavity before the treatment [23]. The best time to repair perforations is immediately after occurrence $[7,8,15,24]$ according to some authors who said that time is the most important factor to expect the treatment outcomes [15]. For the perforation size, perforation with large size don't response to the treatment like the small one $[15,20,25]$. For the perforation location, all studies agree that perforations in the apical and middle third of the root have more favorable prognosis than in the cervical third or furcation area [18].

Treatment of perforations is indicated when teeth are strategically important [10], while this treatment aims to preserving proximal tissues healthy and without occurrence and/or continues of the inflammation and losing the periodontal attachment [24]. A lot of materials had been used to management perforations in primary and permanent teeth in order to attempt an ideal material that achieves: good sealing ability [6], biocompatibility, nontoxic or non-carcinogenic, bactericidal or bacteriostatic, induce osteogenesis and cementogenesis, non-absorbable _in permanent teeth_, dimensionally stable, insensitive to the moisture or blood, easy in manipulation and relatively not expensive [14,27-29]. 
A lot of materials had been suggested to repair perforations such as: Amalgam, calcium hydroxide, calcium hydroxide with iodoform, IRM, Super EBA, light-cured glass ionomer, gutta percha, calcium phosphate, Cavite, composite, Portland cement and MTA [28,30-35]. Although there was no material have the whole ideal properties [14,27-29], MTA has been considered the golden standard in those treatments where it was superior to other tested materials like Amalgam, IRM, Super EBA, GIC and another ones [24,34,36-42].

In primary teeth a few studies have been conducted on repairing furcal perforations which included testing materials like Portland cement, Atelocollagen, MTA cements (Pro Root MTA ${ }^{\circledR}$, MTA Plus ${ }^{\mathrm{TM}}$, Root MTA ${ }^{\circledR}$, Biodentine ${ }^{\mathrm{TM}}$ and CEM $[3,5,29,43-48]$, MTA had been tested also in pulpotomy treatment in primary molars with high success rates [49-55]. Our study in part 2 aims to testing the activity of MTA in repairing mechanical furcal perforations in primary teeth that occurs during pulpotomy procedure and search in the other factors that may affect the prognosis of the treatment.

\section{Theory:}

The treatment of furcal perforated-primary teeth has been considered important in strategically important teeth. There was no treatment of these cases, and the affected teeth were immediately extracted with or without later space maintainer _which has a lot of disadvantages_. In cases without space maintainers application, an occlusion disorders may be occur and lead to functional, morphological and ethical problems. If we don't treat these cases, or let them with an inappropriate material, it will lead to inflammation response and periodontal abscess formation subsequently losing these teeth. We have used MTA cement _the gold standard in repairing perforations in permanent teeth_to repair furcal perforations in primary teeth to preserve these teeth until the natural exfoliation.

\section{Materials \& Methods:}

\subsection{Study design:}

An Uncontrolled clinical trial on upper and lower primary molars; with iatrogenic furcal perforations that occurred during pulpotomy procedure. They had been followed clinically and radiographically within 12 months from the treatment date. Sample of the study was calculated and followed within 3 years, It had been approved by the research ethics committee of Tishreen University (No. 3532/ 14. July. 2015).

The study sample included 34 primary molars for 32 healthy children of the patients in pediatric dental clinic of the faculty of dentistry in Tishreen university- Syria; which were perforated during pulpotomy procedures by pre-graduated students. Patients were transferred to the department of pediatric dentistry. We ensured from the 
medical history which includes systematic problems that conjunct with the treatment. We talked to the parents about the treatment, and the written concept was taken. Sample size was determined by using statistical sampling method to achieve $95 \%$ confidence interval and 5\% accuracy according to our pilot study of four cases which recorded $75 \%$ success rate. Results showed that sample size should be at least 17 subjects to achieve $95 \%$ confidence interval, so we treated 34 cases to obtaining the largest retention rate of treated patients in our study and minimize dropout rate.

Study sample included teeth those previously concepted for pulpotomy treatment which furcation was perforated mechanically; for immediate treatment, and teeth which previously filled with sub-base material of ZOE since no more than one week for the mediate treatment. We excluded the following: tooth that cariously perforated, tooth which pulpotomy procedure was not the real indication, uncontrolled bleeding from the canal orifices during pulpotomy, un-restorable teeth, and when there was no rubber dam application or saliva contamination during pulpotomy.

\subsection{Study procedure:}

\subsubsection{Clinical procedure:}

\subsubsection{Perforation diagnosis:}

Clinical examination was the main criteria for diagnosis without using radiographic imaging. The visually aggressive bleeding from the furcation area and probing it by a gingival probe were the main ways for diagnosis after conjunction all other causes of bleeding in these area by removing residual roof of the pulp chamber completely, amputating inflamed-coronal pulp, and removing the pulp debris adequately. All those procedures were done with copious irrigating of saline solution. Because of the uncooperative behavior of the children after long chair time, only post treatment diagnostic periapical radiographs were taken instead of the pre-treatment radiographs, which ensured the presence of the perforation and would serve as a comparative baseline for future films.

\subsubsection{Perforation treatment:}

After perforations had been diagnosed, the treatment had done as following:

\subsection{Immediate treatment:}

We cleaned the work area, ensured that rubber dam in the right place, and irrigated the pulp chamber and perforation site with copious saline solution, then a moist cotton pellet of $2.5 \%$ Sodium Hypochlorite (SH) (Al-Fares, Damascus, Syria) was placed in the perforation site to control bleeding and disinfect perforation site with surrounding tissues until mixing white Mineral Trioxide Aggregate cement WMTA (MTA Cem ${ }^{\circledR}, \mathrm{NEXOBIO}$, Chungcheongbuk-do, Korea) -excess moisture obstruct the setting of MTA and affect its properties [56]- then material was transferred to the cavity by an amalgam carrier and condensed slightly to the wanted place in $3 \mathrm{~mm}$ 
thickness by a cotton pellet damped with sterile water and squeezed well. Then teeth were restored with Glass lonomer Cement GIC (Cavitan ${ }^{\circledR}$ Plus, SpofaDental, Markoca, Jicin, Czech), and then periapical radiographs were taken to ensure that MTA and GIC in the right place.

\subsection{Mediate treatment:}

Treatment of perforations was introduced as soon as possible (no more than one week after the initial treatment of pulpotomy). After radiographic imaging and visibility of the perforation with excess sub-base material of $\mathrm{ZOE}$, local anesthesia with lidocaine hydrochloride $2 \%$ and epinephrine 1:100,000 was introduced (Huons Lidocaine $\mathrm{HCl}$, Seocho-gu, Seoul, Korea), and then rubber dam was placed in site. Then restoration and sub-base material were removed completely, opening access was completed and residual pulp tissues were removed when we needed that, also we removed little debris of sub-base material (ZOE) and necrotic tissues which were a result of Formocresol FC application during pulpotomy procedure by a sterile dentinal excavator, all that was done under a copious irrigating with saline solution, and then we applied a moistened cotton pellet with $2.5 \% \mathrm{SH}$, and work had completed as the immediate ones.

At the next appointment after one week, all teeth were prepared for restoring with appropriate stainless steel crowns (3M ESPE, st. Paul, USA), then they were adhered with GIC (Kavitan ${ }^{\circledR}$ CEM, SpofaDental, Markoca, Jicin, Czech). Debris was removed from the gingival sulcus and interproximal surfaces by using the dental probe and dental floss.

In both treatments, we instructed parents to call us immediately if pain or discomfort occurred following treatment.

\subsubsection{MTA preparation:}

MTA is usually mixed according to the manufacturer instructions with $3: 1$ ratio powder/sterile water (solution) to achievement a past capable to transferring to the application site. We can alter the ratio to obtaining an appropriate consistency for the work according to the amount of material we need to apply and type of used MTA. Here, and because of the $1 \mathrm{~g}$ powder amount of MTA witch is enough for many applications; we depended on the achievement pasty texture as an appropriate consistency for repairing perforations and also as a sub-base material for pulpotomy. Material had been mixed with sterile water on a clean glass plate by using sterile spatula until achievement the required consistency. Mixed was transferred to the pulp chamber by using an amalgam carrier, and debris thrown after the operation.

\subsection{Clinical \& radiographic evaluation:}

All treatments procedures, clinical and radiographic examinations were introduced in the department of pediatric dentistry by one person. The baseline clinical and 
radiographic evaluation was done at the treatment time. Clinical evaluations were performed at the $1^{\text {st }}$ week after treatment, then at the $3^{\text {rd }}, 6^{\text {th }}, 9^{\text {th }}$, and $12^{\text {th }}$ month, while radiographic evaluations were only at $6^{\text {th }}$ and $12^{\text {th }}$ month after repairing perforations. Then whole evaluation was done by two independent specialists in pediatric dentistry.

We considered case clinically successful when the examined tooth was functionally active and without pathologic symptoms and/or signs such as the presence of pain, gingival redness, abscess, fistula or pathologic movement, and they considered clinically failed when there was any one of the previous signs or symptoms, according to that affected tooth was extracted immediately. On the other hand, case was considered radiographically successful when there was no pathologic radiographic signs such as furcal and/or periradicular radiolucency, pathologic internal/external resorption, canals obliteration, or extension of the ligament space that does not excess double of the normal space, and considered failed when there was any of the last signs. In overall evaluation we had calculated total success and failure, and considered case totally failure when it was clinically failure at any of the follow-up periods, or radiographically failure at the end of $12^{\text {th }}$ month. It was considered totally success when it was clinically successful at all follow-up periods and radiographically at the last ones.

\subsection{Statistical analysis:}

The statistical analysis had been performed by using SPSS bundle version 19 (SPSS Inc., Chicago, IL, USA). We used fisher exact test at 95\% confidence interval and $p$-value 0.05 , to finding the significant statistically differences when the probability values were smaller than or equal to 0.05 . Relative Risk RR also had been used to test the risk of failure according to the perforation size and continues bleeding. All statistical analyses had been done by the researcher.

\section{Results:}

We had treated 34 furcal perforated-molars to 32 children (20 male and 12 female) with age ranged from 5 to 10 years (Mean $=7.7 \pm 0.15$ year), these cases had followed clinically and radiographically for 12 months after the initial treatment and some cases for more than that. We had 6 failure cases, 5 of them had been extracted because of the clinical and/or radiographic failure during the follow-up period.

All teeth were asymptomatic at the first week with a success rate $(100 \%)$. Overall success rate was $79.3 \%$ at $12^{\text {th }}$ month. Table (1) shows the perforation occurrence according to sex, age, tooth type, tooth position and tooth number, and table (2) shows the distribution of success rates according to the perforation size and continues bleeding at perforation site. 
Table (1) Distribution of the furcal perforation-injuries in the affected pulpotomized primary molars according to sex, age and tooth type, number and position

\begin{tabular}{|c|c|c|c|}
\hline & & Teeth number (\%) & Total number \\
\hline \multirow[t]{2}{*}{ Sex } & Male & $20(62.5)$ & \multirow[b]{2}{*}{34} \\
\hline & Female & $12(37.5)$ & \\
\hline \multirow[t]{6}{*}{ Age (years) } & 5 & $2(6.3)$ & \multirow{6}{*}{34} \\
\hline & 6 & $7(21.9)$ & \\
\hline & 7 & $4(12.5)$ & \\
\hline & 8 & $10(31.3)$ & \\
\hline & 9 & $6(18.8)$ & \\
\hline & 10 & $3(9.4)$ & \\
\hline \multirow[t]{2}{*}{ Toot type } & $1^{\text {st }}$ molar & $16(47)$ & \multirow[b]{2}{*}{34} \\
\hline & $2^{\text {nd }}$ molar & $18(53)$ & \\
\hline \multirow{8}{*}{ Tooth number } & 54 & $1(2.9)$ & \multirow{8}{*}{34} \\
\hline & 55 & $2(5.9)$ & \\
\hline & 64 & $1(2.9)$ & \\
\hline & 65 & $2(5.9)$ & \\
\hline & 74 & $2(5.9)$ & \\
\hline & 75 & $11(32.4)$ & \\
\hline & 84 & $12(35.3)$ & \\
\hline & 85 & $3(8.8)$ & \\
\hline \multirow[t]{2}{*}{ Tooth position } & Upper & $6(17.6)$ & \multirow[t]{2}{*}{34} \\
\hline & Lower & $28(82.4)$ & \\
\hline
\end{tabular}

Table (2) Distribution of success rates and relative risk of failure according to perforation size and continues bleeding in the furcation area

\begin{tabular}{|c|c|c|c|c|}
\hline Variables & $\begin{array}{c}\text { Overall success rate } \\
\text { Teeth number (\%) }\end{array}$ & $\begin{array}{c}\text { Relative Risk } \\
\text { for failure (RR) }\end{array}$ & $p$-value \\
\hline $\begin{array}{c}\text { Size of the } \\
\text { perforation }\end{array}$ & Small & $14(87.5)$ & 0.36 \\
\hline $\begin{array}{c}\text { Conge } \\
\text { bleeding }\end{array}$ & Yes & $9(69.2)$ & 2.4 & 1.1 \\
\hline
\end{tabular}

Figure (1) shows clinical and radiographic images for a successful case with immediate treatment with internal resorption and Figure (2) shows clinical and radiographic images for two failure cases with mediate treatment, both cases were with large furcal perforations, all these cases had been treated with MTA immediately for the first case and after one week for the last two cases. 

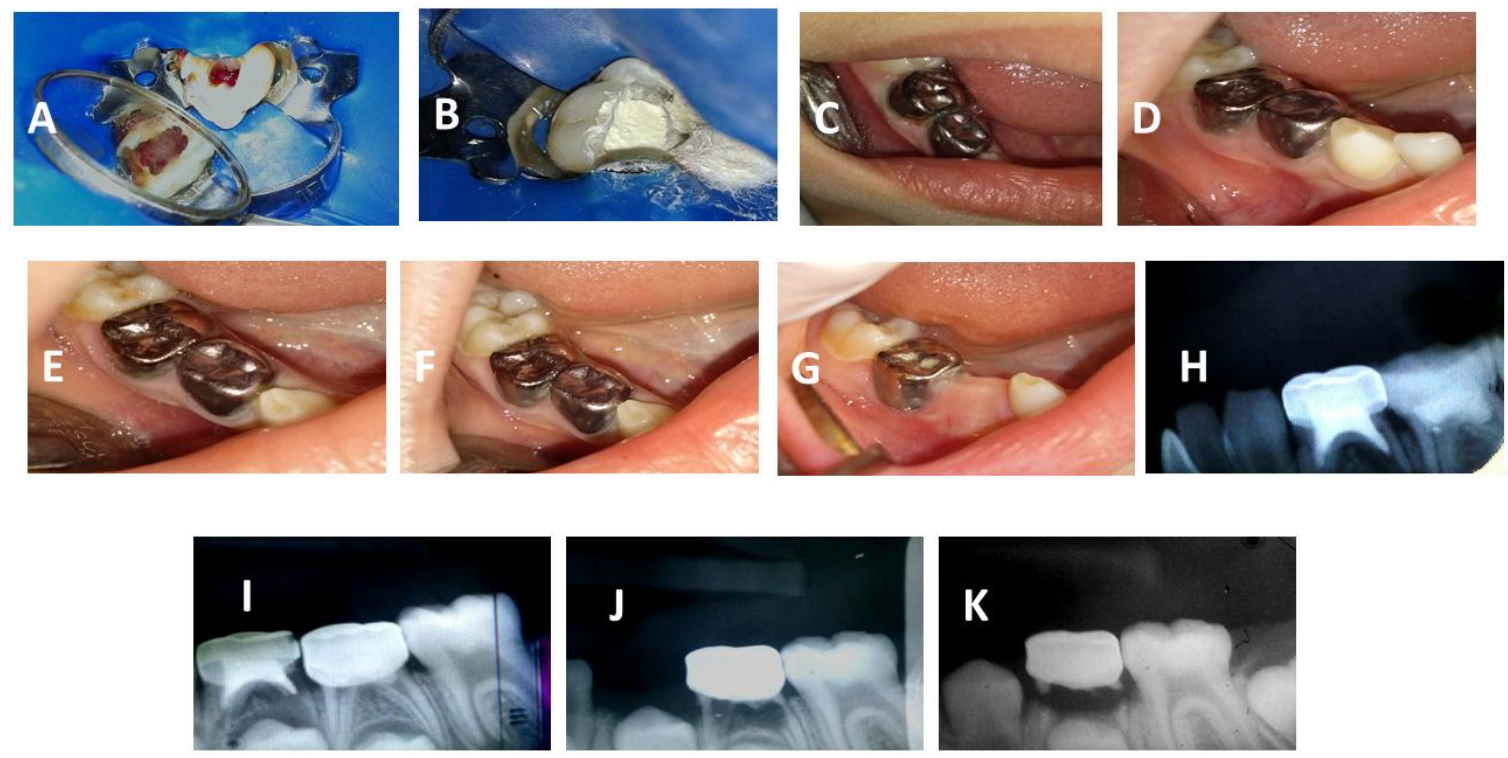

Figure (1) Clinical and radiographic images of second mandibular primary molars: A. perforation detection, B. MTA application, C-D-E-F-G clinically after one week, 6 months, 12, 15 and 24 months respectively. $\mathrm{H}$. radiographically after repairing, I-J-K. Radiographically after 6, 12, 15 months respectively (Internal resorption started at 6th month next to the orifices).
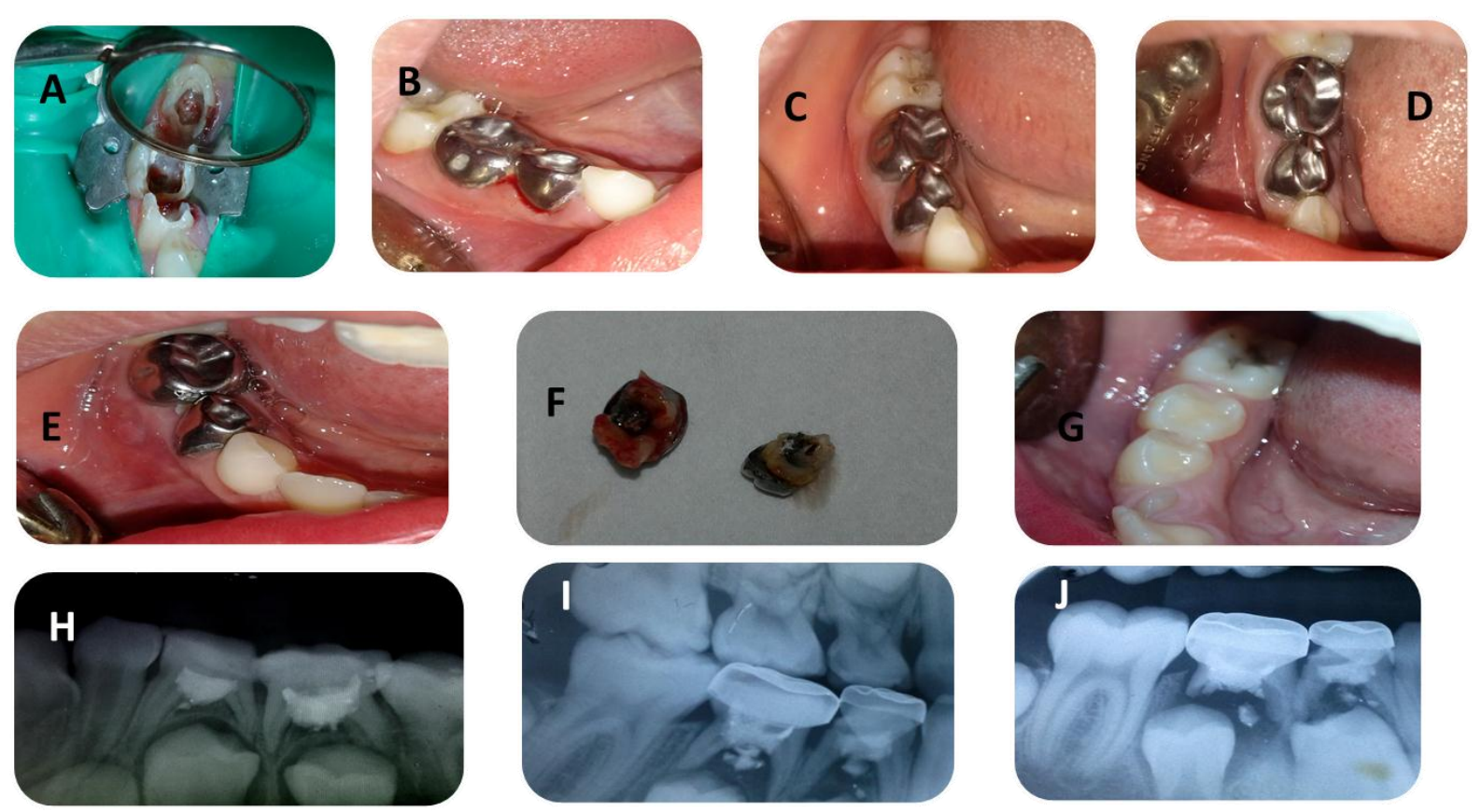

Figure (2) Clinical and radiographic images of two failure cases: A. perforation detection, B. clinically after one week, C. clinically after 3 months, D. clinically after 6 months, E, clinically after 12 months (abscess and gingival redness), F. the extracted teeth, H. radiographically after repairing, I-J. Radiographically after 6 and 12 months respectively (intra-radicular radiolucency) 


\section{Discussion:}

Management of iatrogenic perforations and especially the furcal ones may be an important clinical challenge especially in primary teeth [3], because in generally furcal perforations had the weakest prognosis between root perforations [8], in addition to the presence of the permanent successors under them. MTA and the modified materials from it demonstrated a high sealability, preventing bacterial microleakage and clinical and radiographic healing in three case reports with mediate and immediate treatments and number of in-vitro studies on extracted primary molars with artificial furcal perforations [3,5,29,43,45-48]. There was no clinical research on treating those cases in primary molars and detecting the factors that affected success and failure rates. In our study we had treated 34 furcal perforations of $1^{\text {st }} / 2^{\text {nd }}$ -upper/lower primary molars in uncontrolled clinical trial because that perforation is a procedural accident and we couldn't able to achieve the same conditions in all cases and formatting randomized controlled clinical trial [58].

We didn't detect the size of the perforation in our inclusion criteria because of the differences in type and size of the treated teeth, so we had to estimate the perforation size according to the tooth size, and we considered the whole destruction of the floor of the pulp chamber or the presence of more than one perforation in the floor a large sized-perforation, and except that a small sized-perforation. Criteria of perforation size- assessment in permanent teeth have differed between authors $[15,19,25,65]$, also in primary teeth in-vitro studies were conducted on artificial perforations with different sizes $(0.5$ and 1 and $2 \mathrm{~mm})[5,29,45]$ and they were uniform at every study and there was no comparison between two sizes or more than that. Total evaluation with different sizes refers to a result with no statistical important-difference ( $p$-value $>0.05$ ) but this difference was clinically important. This result agree with what Pontius et al had found in their retrospective study at 2013 on perforations that had been treated by a number of specialists, and said that the larger sized-perforations had decreased the success rate of the treatment [19].

We evaluated the bleeding in the furcation area because of its effect on the repairing treatment and MTA properties like the surface microhardness, compressive strength, marginal adaptation and color of both material and tooth [66-69]. We considered the bleeding continues when it doesn't stop despite of the using of sodium hypochlorite for two minutes, these cases were associated with large perforations because of the large associated injury in the periodontal tissues. A number of researchers found that blood has a negative effect on MTA cement and lead to decrease success rates of treatment $[66,68,70,71]$. In our study there was no statistical important-difference ( $p$-value>0.05) in the overall success rates between the controlled and uncontrolled bleeding-cases, we can attribute the decrease in success rates in the first case to the using of formocresol witch may lead to control the bleeding despite of the good curettage to eliminate all residual necrosis tissues that caused by formocresol, and in the second case to the negative effect of the blood on the material and repairing procedure. One of cases that had an aggressive bleeding was associated with internal resorption next to the orifices. The use of MTA 
and GIC and SSC decreases bacterial microleakage that may lead to later inflammation in the radicular pulp subsequently internal resorption, in addition to that some investigators attributed the occurrence of internal resorption to the presence of Zinc Oxide-Eugenol which hadn't been used in this study. We can attribute the presence of internal resorption to the aggressive bleeding, residual clot in the area or to a previous chronic inflammation in the radicular pulp, and we had considered this case successful because it was asymptomatic at all follow-up periods which reach to 24 months, without involvement of the supporting bone or injury of the permanent successor despite of the perforations that cased by this internal resorption.

\section{Conclusions:}

- $\quad$ MTA can be used as a repair material in furcal perforated- pulpotomized primary molars successfully.

- Small perforations have more favorable prognosis than the large ones.

- Controlled bleeding doesn't have a clear effect on the treatment outcomes especially with the previous using of formocresol in mediate treatments.

\section{References:}

[1]. Barr, E.S; Flaitz, C.M,; Hicks, M.J. A retrospective radiographic evaluation of primary molar pulpectomies. Pediatr Dent.1991;3(1):4-9.

[2]. Parisay, I; Ghoddusi, J; Forghani, M. A review on vital pulp therapy in primary teeth. Iran Endod J. 2015;10(1):6-15.

[3]. El-Khodary; M.H, Farsi, J.D; Farsi, M.N; Zidan, Z.A. Sealing ability of four calcium containing cements used for repairing furcal perforations in primary molars: An invitro study. JCDP . 2015;16(9):733-9.

[4]. Abdul Majeed, H; Trimazi, M.S; Iqbal, N. Furcal perforation repair: MTA versus calcium hydroxide. Pakistan Oral \& Dental J (PODJ.) . 2017;37(2):317-20.

[5]. Samuel, A; Asokan, S; Greetha Priya, P.R; Thomas, S. Evaluation of sealing ability of Biodentine ${ }^{\mathrm{TM}}$ and Mineral Trioxide Aggregate in primary molars using scaning electron microscope: A randomized controlled in vitro trail. Contemp Clin Dent . 2016;7(3):322-25.

[6]. American Association of Endodontists. Glossary of Endodontic Terms, $9^{\text {th }}$. ed. Chicago: American Association of Endodontists, 2016.

[7]. Al-Daafas, A; Al-Nazhan, S. Histological evaluation of contaminated furcal perforations in dog's teeth repaired by MTA with or without internal matrix. Oral Surg Oral Med Oral Pathol Oral Radiol Endod . 2007;103(3):e92-e99.

[8]. Fuss, Z; Trope, M. Root perforations: classification and treatment choices based on prognosis factors. Endod Dent Traumatol. 1996;12(6): 225-264.

[9]. Bargholz, C. Perforation repair with Mineral Trioxide Aggregate: A modified matrix concept.Int Endod J . 2005;38(1):59-69.

[10]. Regan, J.D; Witherspoon, D.E; Foyle, D.M. Surgical repair of root and tooth perforations. Endod Topics. 2005;11(1):152-178. 
[11]. Benenati, F.W; Roana, J.B; Biggs, J.T; Simon, J.H. Recall evaluation of iatrogenic root perforations repaired with amalgam and gutta-percha. J Endod. 1986;12(4):161-6.

[12]. Balla, R; Lomonaco, C.J; Skraibrer, J; Lin, L.M. Histological study of furcation perforations treated with tricalcium phosphate, hydroxylapatite, amalgam and Life. J Endod. 1991;17(5): 234-8.

[13]. Peterson, K; Hasselgren, G; Tronstad, L. Endodontic treatment of experimental root perforations in dog's teeth. Dent Traumatol. 1985;1(1):22-8. [14]. Silveira, C.M; Sanchez-Ayala, A; Laqravere, M.O; Pilatti, G.L; Gomes, O.M. Repair of furcal perforation with Mineral Trioxide Aggregate: Long term follow-up of 2 cases. J Can Dent Assoc. 2008;74(8):729-33.

[15]. Tsesis, I; Fuss, Z. Diagnosis and treatment of accidental rot perforations. Endodontic Topics. 2006;13(1):95-107.

[16]. Fuss, Z; Assooline, L.S; Kaufman, A.Y. Determination of location of root perforations by electronic apex locators. Oral Surg Oral Med Oral Pathol Oral Radiol Endod. 1996 Sep;82(3):324-9.

[17]. Alhadainy, A.H. Root perforations: A review of literature. Oral Surgery Oral Medicine Oral Pathology1994;78(3): 368-74.

[18]. El-Deeb, E.M; El-Deeb, M; Tabibi, A; Jensen, R.J. An evaluation of the use of Amalgam, Cavit and calcium hydroxide in the repair of furcation perforations. JOE. 1982;8(10): 459-66.

[19]. Pontius, V; Pontius, O; Braun, A; Frankenberger, R; Roggendorf, M.J. A retrospective evaluation of perforation repairs in 6 private practices. $J$ Endod. 2013;39(11): 1346-58.

[20]. Gorni, F.G; Andreano, A; Ambrogi, F; Brambilla, E; Cagliani, M. Patient and clinical characteristics associated with primary healing of iatrogenic perforations after root canal treatment: Results of a long-term Italian study. J Endod. 2016;24(2): 211-5.

[21]. Siew, K; Lee, A.H; Cheung, G.S. Treatment outcome of Repaired root perforation: A systematic reviewed meta-analysis. J Endod. 2015;4(11): 1795-804. [22]. Mente, J; Hage, N; Bfefferle, T; Koch, M.J; Geletneky, B; Dreyhaupt, J; Martin, M; Staehle, H.J. Treatment outcome of Mineral Trioxide Aggregate: Repair of root perforations. J Endod. 2010;36(2):208-213.

[23]. Krupp, C; Bargholz, C; Brusehaber, M; Hulsman, M. Treatment outcome after repair of root perforations with Mineral Trioxide Aggregate: A retrospective evaluation of 90 teeth. J Endod. 2013;39(11):1364-8.

[24]. Ford, T.R; Torabinejad, M; McKendry, J.D; Hong, C; Kariyawasam, S. Use of Mineral Trioxide Aggregate for repair of furcal perforations. Oral Surgery Oral Medicine Oral Pathology. 1995;79(6):756-63.

[25]. Alsulaimani, R.S. Immediate and delayed repair of 2 sizes of furcal perforations in gog's teeth using Mineral Trioxide Aggregate cement. J Endod. 2018;44(6): 1000-6. 
[26]. Torabinejad, M; White, D.J. Tooth filling material and method of use. United States Patent 5,769,638, 16 May 1995.

[27]. Main, C; Mirzayan, N; Shabahang, S; Torabinejad, M. Repair of root perforations using Mineral Trioxide Aggregate: A long-term study. J Endod. 2004;30(2): 80-3.

[28]. De-Deus, G; Reis, C; Brandao, C; Fidel, S; Fidel, R.A. The ability of and Portland Cement, MTA and MTA Bio to prevent through-and-through fluid movement in repaired furcal perforations J Endod. 2007;33(11):1374-7.

[29]. El-Tawil, B.S; El-Dokky, A.N; Abd El Hamid, D. Sealing ability of MTA versus Portland cement in the repair of furcal perforations of primary molars: A Day extraction leakage model. Journal of American Science. 2011;7(12):1037-43.

[30]. Hashem, A.A; Hassanien, E.E. ProRoot MTA, MTA-Angelus and IRM used to repair large furcation perforations: sealability study. J Endod. 2008;34(1): 59-61.

[31]. Bramante, C.M; Berbert, A. Influence of time of calcium hydroxide iodoform past replacement in the treatment of root perforations. Braz Dent J1994;5(1):4551.

[32]. Bogaerts, P. Treatment of root perforations with calcium hydroxide and Super EBA cement: a clinical report. IEJ. 1997;30(3): 210-9.

[33]. Alhadainy, H.A; Himel, V.T. Evaluation of the sealing ability of Amalgam, Cavit and glass ionomer cement in the repair of furcation perforations. Oral Surg Oral Med Oral Pathol. 1993;75(3): 362-6.

[34]. Yildirim, T; Gencoglu, N; Firat, I; Perk, C; Guzel, O. Histologic study of furcation perforation treated with MTA or Super EBA in dog's teeth. Oral Surg Oral Med Oral Pathol Oral Radiol Endod. 2005;100(1):120-4.

[35]. De-Deus, G; Petruccelli, V; Gurgel-Filbo, E; Coutinho- Filbo, T. MTA versus Portland Cement as repair material for furcal perforations: A laboratory study using a polymicrobal leakage model. Int Endod J. 2006;39(4):293-8.

[36]. Lee, S.G; Monsef, M; Torabinejad, M. Sealing ability of a Mineral Trioxide Aggregate for repair of lateral root perforations. J Endod. 1993;19(11): 541-4.

[37]. Holland, R; Filho, J.A; de-Souza, V; Nery, M.J; Bernabe, P.F; Junior, E.D. Mineral Trioxide Aggregate repair of lateral root perforations. J Endod. 2001;27(4): 281-4.

[38]. Nakata, T.T; Baek, S; Baumgartner, J.C. Perforation repair comparing MTA and amalgam using anaerobic bacterial leakage model. J Endod.1998;24(3): 1846.

[39]. Ahangari, Z; Karami, M. Evaluation of the sealing ability of amalgam, MTA, Portland Cemant and Goltzol in the repair of furcal perforations. J Endod. 2006;1(2): 60-4.

[40]. Yazdi, K.A; Masoodi, M; Shokohinejad, N. Comparison of tiisu reaction of pulp chamber perforations in dog's teeth treated with MTA, light-cured glass ionomer and amalgam. $\mathrm{J}$ of Dentistry of Tehran University of Medical Sciences. 2006;3(2): 57-62.

[41]. Zhu, Y.Q; Xia, W.W; Xia, L. Histological evaluation on repair of furcation perforation in dogs using MTA. Shanghai Kou Qiany Yi Yue. 2003;12(1): 47-50. 
[42]. Weldon, J.K; Pashley, D.H; Loushine, R.J; Weller, R.N; Kimbrough, W.F. Sealing ability of Mineral Trioxide Aggregate and Super EBA when used as furcation repair materials: A longitudinal study. J Endod. 2002;28(6): 467-70. [43]. Oliveira, T.M; Sakai, T.V; Silva, C.T; Santos, F.C; Machado, M; Abdo, R. Repair of furcal perforation treated with MTA in primary molar teeth: 20-month follow-up. Journal of Dentistry for Children (JDC). 2008;25(2):188-91.

[44]. Masuda, K; Nakano, K; Okawa, R; Naka, S; Matsumoto, M; Ooshima, T. Successful application of Atelocollagen for treatment of perforated teeth. $\mathrm{J}$ Clin Pediatr Dent. 2011;36(1): 1-4.

[45]. Haghgoo, R; Abbasi, F. Treatment of furcal perforation in primary molars with ProRoot MTA versus Root MTA; A laboratory study. Iran Endod J. 2013 Jan;8(2): 52-4..

[46]. Haghgoo, R; Arfa, S; Asgary, S. Microleakage of CEM cement and ProRoot MTA as furcal perforation repair materials in primary teeth. Iran Endod J., 2013 Oct;8(4): 187-90.

[47]. Marques, N.CT; Neto, L.N; Oliveira, T.M. Immediate and mediate furcal perforation treatment in primary molars: 24-month follow-up. Eur Arch Paediatr Dent. 2016;17(6): 489-94.

[48]. Katge, F.A; Shivasharan, P.R; Patil, D. Sealing ability of Mineral Trioxide Aggregate Plus ${ }^{\mathrm{TM}}$ and Biodentine ${ }^{\mathrm{TM}}$ for repair of furcal perforation in primary molars: An in vitro study. Contemp Clin Dent. 2016;7(4): 487-92.

[49]. Agamy, H.A; Bakry, N.S; Mounir, M.MF; Avery, DR. Comparison of mineral trioxide aggregate and formocresol as pulp capping agents in pulpotomized primary teeth. Pediatr Dent. 2004;26(4): 302-9.

[50]. Maroto, M; Barberia, E; Vera, V; Garcia-Godoy, F. Dentin bridge formation after white mineral trioxide aggregate (white MTA) pulpotomies in primary molars. Am J Dent. 2006;19(2): 75-9.

[51]. Maroto, M; Barberia, E; Vera, V; Garcia-Godoy, F. Mineral trioxide aggregate as pulp dressing agent in pulpotomy treatment of primary molars: $42-$ month clinical study. Am J Den.t. 2007;20(5): 283-6.

[52]. Farsi, N; Alamoudi, N; Khalid Balto, K; Mushayt, A. Success of mineral trioxide aggregate in pulpotomized primary molars. J Clin Pediatr Dent. 2005;29(4):307-12..

[53]. Holan, G; Eidelman, E; Fuks, A.B. Long-term Evaluation of Pulpotomy in Primary Molars Using Mineral Trioxide Aggregate or Formocresol. Pediatr Dent. 2005;27(2): 129-36.

[54]. Noorollahain, H. Comparison of mineral trioxide aggregate and formocresol as pulp medicaments for pulpotomies in primary molars. Br Dent $\mathrm{J} 2008$; 204 : Published online: 18 April 2008 doi:10.1038/sj.bdj. 2008.319.

[55]. Godhi, B; Sood, P.D; Sarma, A. Effect of mineral trioxide aggregate and formocresol on vital pulp after pulpotomy of primary molars: An in vivo study. Contemporary clinical dentistry $2011 ; 2(4)$ : 296-301.

[56]. American Academy of Pediatric Dentistry. Use of Vital Pulp Therapies in Primary Teeth with Deep Caries Lesions. Pediatr Dent. 2018/2019;40(6):179-92. [57]. Smith, N.L; Sue Seale, M.SN; Nunn, M.E. Ferric sulfate pulpotomy in primary molars: A retrospective study. Pediatr Dent. 2000;22(3):192-9. 
[58]. Torabinejad, M; Parirokh, M; Dummer, P.MH. MTA and other bioactive endodontic cements: An updated overview-part II: Other clinical applications and complications. Int Endod J. 2018;51(2):284-317.

[59]. Bramante, C.M; Berbert, A. Root perforations dressed with calcium hydroxide or zinc oxide and eugenol. J Endod. 1987;13(8):392-5.

[60]. Parirokh, M; Torabinejad, M. Mineral Trioxide Aggregate: A comprehensive literature review-Part I: Chemical, physical and antibacterial properties. $J$ Endod. 2010;36(1): 16-27.

[61]. Eidelman, E; Holan, G; Fuks, A.B. Mineral trioxide aggregate vs. formocresol in pulpotomized primary molars: a preliminary report. Pediatr Dent2001;23(1): 158.

[62]. Percinoto, C; Castro, A.M.; Pinto, L.M. Clinical and radiographic evaluation of pulpotomies employing calcium hydroxide and trioxide mineral aggregate. Gen Dent. 2006;54(4): 258-61.

[63]. TORABINEJAD, M. Mineral Trioxide Aggregate, Properties and Clinical Applications. $1^{\text {st }}$. ed., John Willey \& Sons, Inc California, USA, 2014.

[64]. Sarkar, N.K; Caicedo, R; Ritwik, R; Moiseyeva, R; Kawashima, I. Physiochemical basis of the biologic properties of Mineral Trioxide Aggregate. $\mathrm{J}$ Endod. 2005;31(2): 97-100.

[65]. Shah, D.Y; Khopadel, S.HT; Jain1, P.M; Dadpe, A.M. Delayed repair of multiple perforations compounded with formocresol osteo-gingival necrosis. Saudi Endodontic Journal. 2018;8(1): 50-4.

[66]. Nekoofar, M.H; Aseeley, Z; Dummer, D.MH. The effect of various mixing techniques on the surface microhardness of Mineral Trioxide Aggregate. Int Endod J. 2010;43(4): 312-20.

[67]. Oloomi, K; Saberi, E; Mokhtari, H; Zonouzi, H.R; Nosrat, A; Nekoofar, M.H; Dummer, P.MH. Evaluation of the effect of blood contamination on the compressive strength of Mineral Trioxide Aggregate modified with hydration accelerator. Restor Dent Endod. 2013;38(33): 128-33.

[68]. Milani, A.S; Rahimi, S; Froughreyhani, M; Pakdel, M.V. Effect of blood contamination on marginal adaptation and surface microstructure of Mineral Trioxide Aggregate: A SEM study. J Dent Res Dent Cli Dent Prospects. 2013;7(3): 157-63.

[69]. Lenherr, P; Allgayer, N; Weiger, R; Filippi, A; Attin, T; Krastl, G. Tooth discoloration induced by endodontic materials: a laboratory study. Int Endod J. 2012;25(10): 942-9.

[70]. VanderWeele, R. A; Schwartz, S. A; Beeson, T. J. Effect of blood contamination on retention characteristics of MTA when mixed with different liquids. Journal of Endodontics. 2006;32(5): 421-4.

[71]. Nekoofar, M. H; Davies, T. E; Stone, D; Basturk, F.B; Dummer, P.M. Microstructure and chemical analysis of blood-contaminated mineral trioxide aggregate. International Endodontics Journal. 2011;44(11): 1011-8.

[72]. Mutluay, M; Arikan, V; Sari, S; Kisa, U. "Does Achievement of Hemostasis After Pulp Exposure Provide an Accurate Assessment of Pulp Inflammation?". Pediatr Dent. 2018;40(1): 37-42. 